\section{Fatores Envolvidos na Reatividade do PPD em Pacientes com Doença de Hansen}

\author{
Nádia Cristina Düppre* \\ Maria Fernanda Sardella Alvim* \\ Maria Eugenia Noviski Gallo* \\ José Augusto da Costa Nery* \\ Euzenir Nunes Sarno*
}

*Pesquisadores do Ambulatório Souza Araújo - Setor de Hansentase - Fiocruz

Foram testados intradermicamente com PPD (RT23 e FAP 5U) 236 pacientes hansenianos (138 multibacilares e 98 paucibacilares) e 291 contatos sadios. Observa-se um percentual menor de reatores ao PPD em pacientes multibacilares (42\%), quando comparados a paucibacilares $(62,2 \%)$ e contatos sadios $(63,2 \%)$.

Entre os pacientes multibacilares, o indice bacteriológico (IB) mostrou ser fator de interferência na resposta ao $P P D$, sendo significativamente maior $o$ percentual de respondedores em pacientes com $I B$ negativo, quando comparados aos com IB igual ou acima de 3. Foi observado um elevado índice de positividade à tuberculina em contatos sadios $(61,0 \%)$ e pacientes paucibacilares $(65,3 \%)$ com teste de Mitsuda positivo.

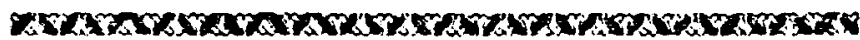

\section{INTRODUÇÃO}

Há evidências de que a resistência à infecção pelo microorganismo intracelular Mycobacterium leprae requer uma eficaz resposta imune mediada por células. Os aspectos clínicos e a evolução da Hanseníase dependem da extensão desta resposta ao microorganismo que, por sua vez, controla a multiplicação bacilar (14).

No pólo tuberculóide, onde se observa uma evidente imunidade celular, o crescimento bacteriano e a disseminação são controlados. No pólo lepromatoso, onde pouca ou nenhuma imunidade celular está presente, a multiplicação bacilar se estende por toda a derme. Entre as duas formas clínicas, um grupo de pacientes denominado borderlines apresenta variado grau de resistência, classificando-se em borderline tuberculóide (BT), borderline borderline (BB) e borderline lepro- 
matoso (BL), segundo uma progressiva redução da resposta imune celular ao antígeno $(6,12)$.

Os testes cutâneos de hipersensibilidade retardada ao $M$. leprae e ao PPD têm sido de há muito utilizados como avaliadores da resposta imune aos respectivos antígenos. Stanley e col (17) demonstraram que, entre crianças naturalmente $\mathrm{PPD}$ positivas, ocorreram $58 \%$ menos casos de hanseníase do que entre os PPD negativos. Por outro lado, Smelt e col (15) documentaram que, vacinando com $\mathrm{BCG}$ pacientes lepromatosos $P P D$ negativos, se podia induzir resposta positiva à tuberculina, sem causar qualquer aumento na resposta ao $M$. leprae.

Talwar e col (19), em seu estudo, realizaram testes cutâneos de PPD e $M$. leprae em 10 pacientes lepromatosos e observaram que, embora todos tivessem resultados do teste de Mitsuda negativos, quatro deles foram positivos ao PPD.

Há referências de uma diminuição na resposta cutânea ao PPD em pacientes multibacilares, quando comparados a pacientes paucibacilares e a contatos sadios de pacientes com hanseníase $(2,4,5)$.

Guinto e col (4), em trabalho realizado na Província de Cebu, com pacientes lepromatosos, tuberculóides e controles sadios, encontraram um percentual de positividade ao PPD $5 U$ de $47,4 \%, 61,2 \%$ e $81,3 \%$, respectivamente.

Outros autores relataram que, após o tratamento, a média das respostas ao PPD em pacientes lepromatosos se eleva, embora seja menor que no grupo de contatos sadios, sugerindo que a inibição cutânea a determinantes antigểnicos do PPD, que não estão presentes no indivíduo antes do tratamento, seja restabelecida após o tratamento, enquanto que a falta de resposta a determinantes do $M$. leprae permanece (11).

Dados similares são descritos por Cree e col (2) que, ao analisarem a resposta ao PPD em pacientes de hanseníase, observaram que pacientes paucibacilares e multibacilares não-tratados têm um número menor de reações positivas quando comparados ao grupo de pacientes tratados, associando, portanto, o tratamento ao aumento da produção de resposta cutânea a antígenos de micobactérias.

$O$ presente estudo propõe-se a investigar a hipersensibilidade tipo tardia ao PPD (HTT) em pacientes pauci e multibacilares, associando a variabilidade das reaçōes ao teste de Mitsuda, tempo de tratamento e índice bacilar, comparando estas respostas às da população-controle de contatos sadios.

\section{MATERIAL E MÉTODOS}

Este estudo foi realizado no Ambulatório Souza Araújo, Setor de Hanseníase, Fiocruz, no período de 
junho de 1987 a setembro de 1989. Foram testados com PPD 5U FAP (Fundação Ataulpho de Paiva) e PPD RT 23, 138 pacientes multibacilares (BL e $L L)$, 98 paucibacilares (I e BT) e 291 contatos sadios, intra e extra domiciliares de pacientes com hanseníase examinados neste serviço.

Os pacientes foram submetidos a esquema de multidrogaterapia, com tempo de tratamento variado, e classificados clínica e histopatologicamente segundo Ridley-Jopling (12). O número de pacientes, em cada grupo, é mostrado na tabela I.

\section{TABELA I}

Número de Pacientes de Hanseníase, de Acordo com

Tempo de Tratamento e Classificação

de Ridley-Jopling

\begin{tabular}{llllll}
\hline $\begin{array}{l}\text { Tempo } \\
\text { de Tratamento }\end{array}$ & LL & BL & BT & HI & Total \\
\hline & & & & & \\
Năo-Tratados & 17 & 20 & 18 & 23 & 78 \\
Em tratamento & 36 & 51 & 19 & 14 & 120 \\
Em EOSTO * & 11 & 03 & 18 & 06 & 38 \\
\hline Total & 64 & 74 & 55 & 43 & 236 \\
\hline
\end{tabular}

*Os pacientes em EOSTO (em observação, sem tratamento quimioterápico) são aqueles já tratados, com a medicação específica suspensa, em perfodo de observação clínica.

\section{TESTES CUTÂNEOS}

Previamente à introduçāo na multidrogaterapia, todos os pacientes foram testados com lepromina integral ou lepromina de Tatu. Foi injetado intradermicamente $0,1 \mathrm{ml}$ da solução no terço inferior do antebraço E, e a leitura feita após 21 ou 30 dias da aplicação. Foi considerada negativa a reaçăo $\leqslant 2 \mathrm{~mm}$ e positiva a reação $\geqslant 3 \mathrm{~mm}(7)$.

O PPD 5U FAP (PPD produzido na Fundaçāo Ataulpho de Paiva, RJ, Brasil) foi realizado em 94 pacientes e 146 contatos sadios e o PPD RT $23 \mathrm{em}$ 142 pacientes e 145 contatos. A reatividade cutânea, quando se utilizaram ambos os testes, para efeito de comparação, demonstrou ao PPD RT 23 um aumento 
no número de reatores de $10,5 \%$. Os resultados foram computados conjuntamente.

A aplicação foi feita por via intradérmica, com $0,1 \mathrm{ml}$ de PPD no terço médio da face anterior do antebraço esquerdo. A leitura do teste foi realizada 48 ou 72 horas após a aplicação, e a induração com diâmetro maior ou igual a $5 \mathrm{~mm}$ foi considerada positiva.

O material utilizado e as técnicas de aplicação e leitura foram aquelas preconizadas pela OMS (1).

\section{RESULTADOS}

A resposta ao PPD em 138 pacientes multibacilares, 98 paucibacilares e 291 contatos sadios foi comparada a trabalhos anteriores de resposta à tuberculina, quando se detectaram $82 \%$ de reatores em 6.673 individuos do sexo masculino, maiores de 15 anos, supostamente sem contatos com pacientes de hanseníase (9). $O$ percentual da reatividade obtido no presente trabalho foi de $42,0 \%$ em multibacilares, $62,2 \%$ em paucibacilares e $63,2 \%$ em contatos sadios (Fig. 1). Foi estatisticamente significante o menor número de reatores multibacilares, quando comparados a todos os outros grupos testados $10<\mathrm{p}<5$.

\section{FIGURA 1}

Percentual de Reatores à Tuberculina em Pacientes de Hanseníase por Forma Clínica, em Contatos Sadios de Pacientes e População em Geral, Presumivelmente Sem Contatos com Hanseníase

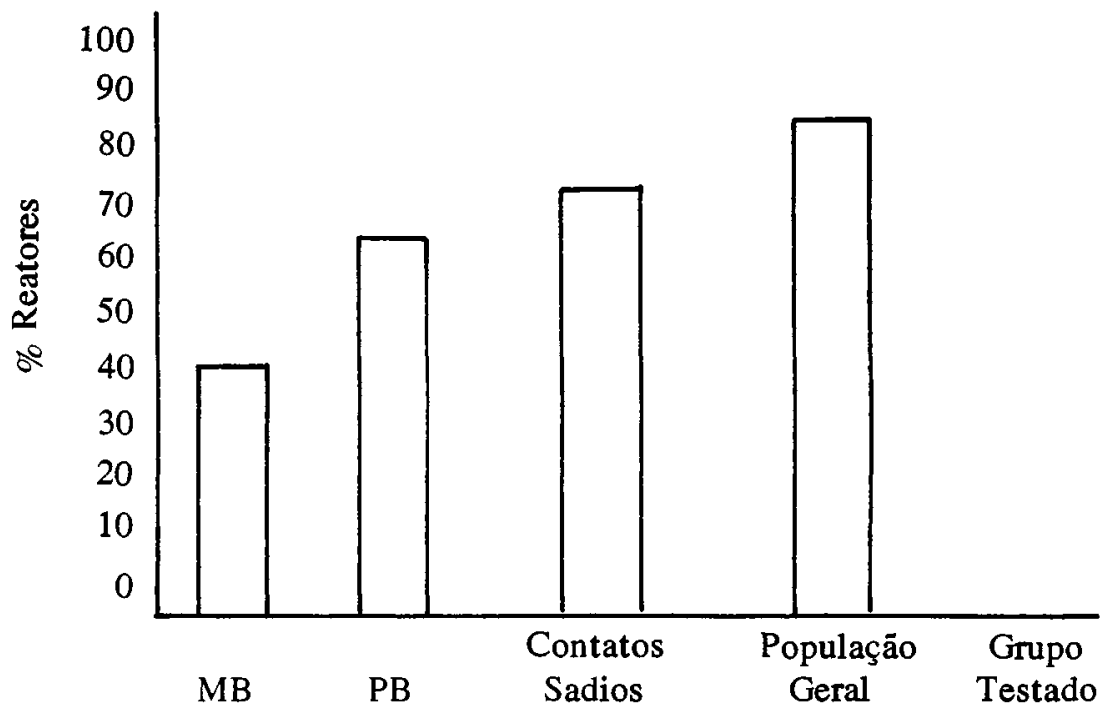


Entre pacientes paucibacilares e contatos sadios, não houve diferença significativa no percentual de respondedores, porém, a alta reatividade da população geral foi estatisticamente significante, quando comparada com estes dois grupos $10<p<5$.

A distribuição da reatividade ao PPD segundo a faixa etária é demonstrada na tabela II. Quando comparamos o percentual de reatores à tuberculina em pacientes multi e paucibacilares, observamos que a diferença de positividade não foi significativa na faixa etária de 6 a 14 anos; porém, naqueles pacientes com idade superior a 15 anos, a diferença no percentual de reatores foi estatisticamente significante $(5<\mathrm{p}<2)$. Também a população geral com idade superior a 15 anos apresentou um percentual de positividade significativamente maior, quando comparada a contatos sadios nas mesmas faixas etárias $(\mathrm{p}<0,1)$.

\section{TABELA II}

Distribuição da Resposta à Tuberculina, Segundo Grupo Etário, em Pacientes com Hanseníase, Contatos Sadios e População Geral

\begin{tabular}{lccccccccccc}
\hline \\
$\begin{array}{l}\text { Pestada } \\
\text { Populaçä́ }\end{array}$ \\
\hline
\end{tabular}

*A população geral é composta de indivíduos do sexo masculino, com idade superior a 15 anos de idade. 
Foi indagado a todos os indivíduos testados sobre a possibilidade de um prévio contato com pacientes que, sabidamente, haviam adoecido com tuberculose, e a resposta ao PPD foi avaliada segundo a referência desta, afirmativa ou negativa. Observou-se que, naqueles que referiam contato prévio, houve um aumento significativo $(\mathrm{p}<0,1 \%)$ no número de reatores, tanto em multibacilares, paucibacilares, como em contatos sadios, quando comparados àqueles que negavam conhecimento deste tipo de contato; porém, o aumento no número de respondedores foi proporcional, em todos os grupos.

Com relação às formas clínicas, não foi significativa a diferença na proporção de respondedores em pacientes BL e LL $(37,8$ e $46,0 \%)$, respectivamente, e em pacientes I e BT $(69,8$ e $56,4 \%)$, respectivamente.

O tempo de tratamento pareceu não estar associado à resposta cutânea ao PPD, pois o percentual de positividade em multibacilares virgens de tratamento $(40,5 \%)$ e em tratamento $(42,6 \%)$ não apresentou diferença significativa, o mesmo ocorrendo no grupo de pacientes paucibacilares, $61,0 \%$ em virgèns de tratamento e $63,0 \%$ naqueles em tratamento.

$\mathrm{Na}$ tabela $\mathrm{II}$, observamos que os pacientes paucibacilares e contatos sadios com teste de Mitsuda positivo $(\geqslant 3 \mathrm{~mm})$ apresentaram um percentual significativamente maior de reatores ao PPD. Naqueles com teste de Mitsuda negativo, tal diferença não foi observada em paucibacilares; já entre os contatos sadios, houve um número significativo de não-reatores ao $\mathrm{PPD}$ $(5<\mathrm{p}<2)$.

\section{TABELA III}

Reatividade à Tuberculina em Pacientes Paucibacilares e Contatos Sadios, Segundo o Resultado do Teste de Mitsuda

\begin{tabular}{lcccccccc}
\hline & \multicolumn{3}{c}{ Contatos Sadios } & \multicolumn{3}{c}{ Pacientes Paucibacilares } \\
\cline { 2 - 9 } Teste de & \multicolumn{2}{c}{ PPD (+) } & \multicolumn{2}{c}{ PPD (-) } & \multicolumn{2}{c}{ PPD (+) } & \multicolumn{2}{c}{ PPD (-) } \\
Mitsuda & N: & $\%$ & N: & $\%$ & N: & $\%$ & N: & $\%$ \\
\hline Mitsuda (+) & 88 & 61,0 & 56 & 39,0 & 47 & 65,3 & 25 & 34,7 \\
Mitsuda (-) & 05 & 23,0 & 17 & 77,0 & 14 & 54,0 & 12 & 46,0 \\
\hline
\end{tabular}

* A concordância dos testes cutâneos em pacientes paucibacilares e contatos sadios foi $70,0 \%$ e $63 \%$, respectivamente. 
$\mathrm{Na}$ tabela IV, observamos que os pacientes multibacilares, apesar de apresentarem um menor percentual de fortes reatores (indurações $\geqslant 10 \mathrm{~mm}$ ), na condição de não-tratados e em tratamento, a sua média de induraçāo assume valores elevados, sendo significativamente maior $(2<\mathrm{p}<1)$ do que os pacientes paucibacilares nas mesmas condições de tratamento.

\section{TABELA IV}

Média de Induração ao PPD em Pacientes de Hanseníase, Segundo Forma Clínica e Tempo de Tratamento

\begin{tabular}{lcccccc}
\hline & \multicolumn{3}{c}{ Multibacilares } & \multicolumn{3}{c}{ Paucibacilares } \\
& $\%$ & $\bar{X}(\mathrm{MM})$ & $\mathrm{SD}$ & $\%$ & $\overline{\mathrm{X}}(\mathrm{MM})$ & $\mathrm{SD}$ \\
\hline Não-Tratados & 40,5 & 19,30 & 7,47 & 61,0 & 14,0 & 3,15 \\
Em Tratamento & 41,4 & 19,0 & 10,5 & 61,0 & 13,60 & 3,77 \\
Em EOSTO & 42,8 & 16,60 & 7,0 & 67,0 & 16,01 & 5,43
\end{tabular}

Em pacientes multibacilares, associando a resposta da tuberculina ao índice baciloscópico (IB), podemos observar que a positividade ao PPD foi significativamente maior $(5<p<2)$ naqueles com IB negativos, quando comparados àqueles com IB maior ou igual a 3 (Figura 2).

\section{FIGURA 2}

Resultados da Reatividade ao, PPD em Pacientes Multibacilares com Relação ao Índice Bacteriológico

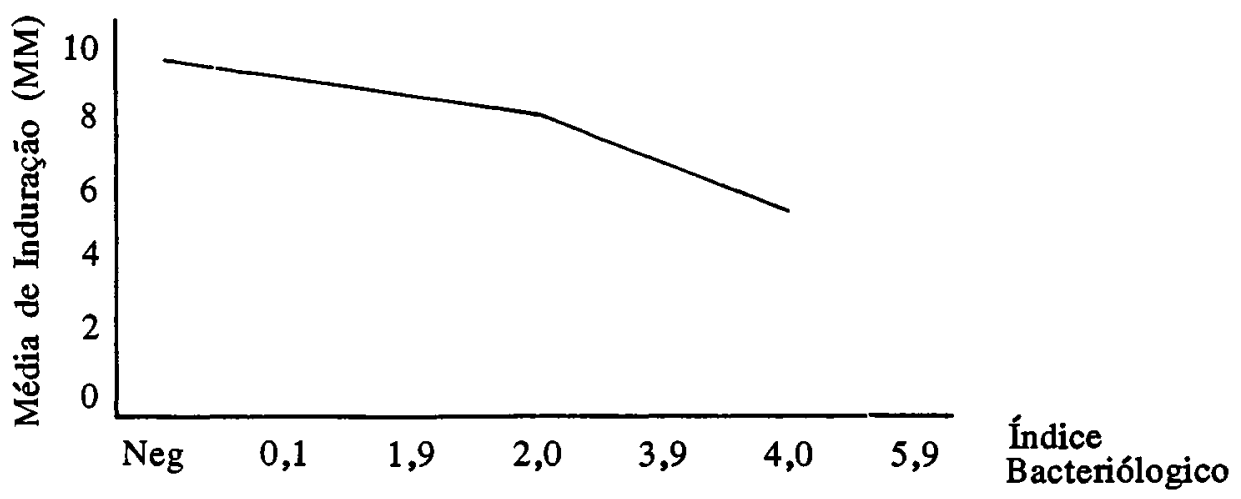




\section{DISCUSSÄO}

Vários estudos realizados até o momento, avaliando a reatividade à tuberculina em pacientes multibacilares, paucibacilares e contatos sadios, apontam um baixo índice de PPD positivo em pacientes multibacilares, quando comparados a pacientes paucibacilares e a contatos sadios $(2,4,5,10)$.

Em nosso estudo, observamos que os pacientes paucibacilares e os contatos sadios, apesar de serem mais reatores ao PPD do que os pacientes multibacilares, năo apresentam, entre si, diferença no percentual de reatores, porém foram menos respondedores do que a população sadia, supostamente sem contatos com hanseníase. Este dado confirma o estudo de Fernandez (3), quando observou que também os contatos de pacientes com hanseníase, apesar de não apresentarem manifestaçōes clínicas da doença, convivem com o doente $\mathrm{e}$, indiscutivelmente, eståo em contato com o bacilo de Hansen e, portanto, reagem imunologicamente de modo semelhante aos pacientes e não como pessoas sadias.

Também Guinto e col (4) sugeriram, em seu trabalho, que aquelas pessoas originariamente negativas à tuberculina poderiam ser mais susceptíveis que as outras a adquirirem a forma lepromatosa da doença.

De um modo geral, os pacientes multibacilares responderam menos ao $\mathrm{PPD}$, não havendo diferença entre as formas BL ou LL, o mesmo ocorrendo entre paucibacilares nas formas clínicas BT e I.

Quando se comparou a reatividade ao PPD, associada ao teste de Mitsuda, observou-se um percentual maior de reatores ao PPD em pacientes paucibacilares e em contatos sadios com teste de Mitsuda positivo. Roberts'e col (13), em seu estudo, mostraram que os linfócitos $\mathrm{T}$, extraídos e clonados de biópsia de reação de Mitsuda, são, em sua maioria, específicos para o PPD e não para antígenos do $M$. leprae.

Apesar de vários autores $(2,15)$ associarem aumento da resposta cutânea ao PPD ao tempo de tratamento, em nosso estudo este fenômeno não foi observado, pois não foi significativa a diferença no percentual de reatores, quando se comparou a reatividade cutânea entre aqueles não-tratados e já em tratamento.

O contato com tuberculose foi fator de positivação do PPD, na mesma proporção, em todos os grupos. Observamos que, mesmo os pacientes multibacilares que são imunodeprimidos ao $M$. leprae, quando em contato com pacientes tuberculosos, foram reatores ao PPD, concordando com Strickand (18), quando afirma que os pacientes lepromatosos, que são incapazes de ter uma resposta imune celular contra antígenos específicos ao $M$. leprae, podem ter, apesar disso, 
uma resposta normal a outros antígenos dependentes de células $T$.

Avaliando as respostas ao PPD consideradas como fortes reatores ( $\geqslant 10 \mathrm{~mm}$ ), podemos observar que, entre os pacientes multibacilares, apesar de apresentarem, um menor número de respondedores, o diâmetro de suas respostas foi exacerbado, com média de induraçāo significativamente maior do que os pacientes paucibacilares.

$\mathrm{Em}$ quatorze pacientes multibacilares com estas reações exacerbadas ao PPD, foi observado um quadro de sintomatologia geral como dor, edema e eritema acentuados no local do teste, febre, infartamento ganglionar e mal-estar geral, quadro este observado por outros autores $(16,20)$ e que foi caracterizado como "Reação Gigante". Eles admitem que, embora o mecanismo dessas respostas não esteja bem entendido, ele pode estar associado a uma hipersensibilidade à tuberculina, e pode ocorrer durante um período de falta de regulação imune, associada a variações nos níveis de carga antigênica.

Em pacientes paucibacilares e contatos sadios, não foi observada sintomatologia semelhante, embora também houvesse entre eles indurações com valores acima de $20 \mathrm{~mm}$.

Sob todos os aspectos analisados, observamos que, em multibacilares, a carga bacilar foi fator de depressão da reatividade cutânea ao PPD, pois aqueles com índice baciloscópico (IB) maior ou igual a três apresentaram um número significativamente menor de respondedores, quando comparados a pacientes com índice baciloscópico negativo.

Kaplan e col (8), em seu estudo, sugeriram que a resposta imune celular em pacientes lepromatosos pode estar suprimida, em parte, pela alta concentração de produtos bacilares ou por outros mecanismos tissulares presentes no organismo do indivíduo.

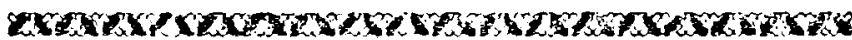

PPD (Purified Protein Derivative) was injected intradermally in 236 leprosy patients (138 of multibacillary form and 98 paucibacillary), 291 healthy household leprosy contacts.

The less reactive population to PPD was composed of multibacillary patients with a positivity rate of $42 \%$, $62,2 \%$ for paucibacillary and $63,2 \%$ for contacts. Among the multibacillary patients the BI (Bacteriological index) seems to interfere with $P P D$ reactivity. It was found a significative association 
between negative response to $P P D$ and $B I$ greater than $3+(p<5)$. It was observed high positivity rate to $P P D$ in healthy household contacts $(61,0 \%)$ and paucibacillary leprosy patients $(65,3 \%)$ with positive Mitsuda Skin test.

\section{REFERÊNCLAS BIBLIOGRÁFICAS}

1 - COMISSÃO TÉCNICA DA CAMPANHA NACIONAL CONTRA A TUBERCULOSE. Prova Tuberculínica em Saúde Pública, 2: Recomendaçäo. Rev. Ser. Nac. Tuber culose. XII, 1968, - 219-230.

2 - CREE, I. A.; SMITH, W. C. S.; REES, R. J. W. and SWANSON BECK, J. - The influence of antimycobacterial chemotherapy on delayed hypersensitivity skin-test reactions in leprosy patients. Lepr. Rev. 59 (1988). 145-151.

3 - FERNANDEZ, J. M. M. - Estudio comparativo de la reacción de Mitsuda con las reacciones tuberculf́nicas. Rev. Argent. Dermatosif. 23 (1939) 425-451.

4 - GUINTO, R. S. and MABALAY, M. C. - A note on the tuberculin reaction in leprosy. Int. J. Lepr. 30 (1962) $278-283$.

5 - HALE, J. H.; MOLESWORTH, B. D.; GROVE-WHITE, R. J.; SAMBAMURTHI, C. M. and RUSSEL, D. A. - The relationship and significance of the mantoux and lepromin reactions in leprosy. Int. J, Lepr. 23 (1955) 139-147.

6 - HART, P. D'ARCY and REES R. J. W. - Lepromin and Kveim antigen reactivity in man, and their relation to tuberculin reactivity. Br. Mrd. Bull 23 (1967) 80-55.

7 - INTERNATIONAL CONGRESS OF LEPROSY, 6, 1953. Madrid. Immunology: (Technical resolutions) Int. J. Lepro. sy, New Orleans, 21 (1953) 527-535.

08 - KAPLAN, G.; LAAL, S.; SHEFTEL, G.; NUSRAT, A; NATH, J. and COHN, Z.A. - The nature and kinetics of a delayed immune response to a purified protein derivative of taberculin in the skin of lepromatous leprosy patients. J. Exp. Med. 168, (1988) 1811-24.

09 - NASCIMENTO, E. A.; DIAGO, D. O.; MOURĀO, L. W. E LIMA, M. M. - Cadastro torácico e tuberculfnico na polf́cia militar do Estado da Guanabara. $R$. Serv. Nac. Tuberc. 13 (1969) 265-272.

10 - PINTO - M. R. M. ARSECULERATNE, S. N. and WELIANGA, L. V. - The diferencial tuberculin test in leprosy. Lepr. Rev. 44 (1973) 13-21.

11 - REITAN, L. J. - The specificity of the immunodeficiency in lepromatous leprosy. Lepr. Rev. 57 (1986) 203-205.

12 - RIDLEY, D. S.; JOPLING, W. H. - Classification of leprosy according to immunity: a five group system. Int. J. Lepr. 34 (1966) 255-273. 
13 - ROBERTS, P. P.; DOCKRELL, H. M. and MC ADAM, K. P. W. J. - Evidence that the Mitsuda reaction to Mycobacterium leprae can be mediated by lymphocytes responsive to Mycobacterium tubercolusis. clin. Exp. Immunol. 72 (1988), 390-393.

14 - SANSONETTI, P.; LAGRANGE, P. H. - The Immunology of Leprosy: Speculations on the Leprosy Spectrum. Rev. Infect. Dis. 1 (1981) 422-469.

15 - SMELT, H. M.; REES, R, J. M. and LIEW, F. Y. - Failure to induce delayed - type hipersensitivity to Mycobacterium leprae in long term treated lepromatous leprosy patients. Clin. Exp. Immunol. (1981) 44-507.

16 - STANFORD, J. L. - Skin testing with mucobacterial reagents in leprosy. Tubercle 65 (1984) 63-74.

17 - STANLEY, S. J.; HOWLAND, C.; STONE, M. M. and SUTHER LAND, I. - BCG vaccination of children against leprosy in Uganda, final results. J. Hygiene (1981) 87-233.

18 - STRICKLAND, N. H. - The influence of immunossupression and immunodeficiency on infection with leprosy and tuberculosis. Int. J. Lepr. 53 (1985) 86-100.

19 - TALWAR, G. P.; KRISHNAN, A. D.; MEHRA, V. L.; BLUM, E. A. and PEARSON J. M. H. - Evaluation of cell mediated immune responses in untreated cases of leprosy. Clin. Exp. Immonul 12 (1972) 195-203.

20 - WATERS, M. F. R. and STANFORD, J. L. - Giant reactions to tuberculin in lepromatous leprosy patient. Int. J. Lepr. 53 (1985) 546-553. 